\title{
Exploring barriers affecting eLearning usage intentions: An NLP-based multi-method approach
}

\author{
Arghya Ray ${ }^{1}$, Pradip Kumar Bala ${ }^{2}$, Yogesh K Dwivedi ${ }^{3}$, \\ 1. Adamas University Kolkata 2. Indian Institute of Management Ranchi \\ University- Bay Campus, Swansea, UK. \\ 3. Swansea
}

\section{Corresponding Author:}

\section{Arghya Ray \\ Department of Management, Adamas University, \\ Barasat Barrackpore Road,}

Kolkata, West Bengal, Pin-700126, India.

Email: arghya.ray16fpm@iimranchi.ac.in

Phone: +91-9199166554/+91-9677141745

\section{Co-Authors:}

Pradip Kumar Bala

Information Systems and Business Analytics,

Indian Institute of Management Ranchi, Ranchi,

Suchana Bhawan, 5th Floor, Audrey House Campus,

Meur's Road, Jharkhand, Pin-834008, India.

Email: pkbala@iimranchi.ac.in

Phone: +91-9534072809

Yogesh K Dwivedi

Professor of Digital Marketing and Innovation

Director of Emerging Markets Research Centre

School of Management

Swansea University

Bay Campus, Fabian Way, Swansea, SA1 8EN

Phone: +44 (0)1792 602340

Email: y.k.dwivedi@swansea.ac.uk 


\begin{abstract}
:
With online-learning becoming the new mode of learning, providers need to understand the barriers that learners face. The objective of this study is to utilize a multi-method approach to examine the barriers that affect learner's intention to use e-Learning services. The multi-method approach consists of qualitative semi-structured interviews of 8 participants, topic-modelling on 3227 reviews from Coursera dataset and 463 responses from an online survey for quantitative analysis. The interviews revealed themes like "rigid-course-structure", "complexity", "quality-offacilitator", and "value-addition". The topic-modeling approach extracted themes like, "techniqueof-teaching", "language-of-speaker", “course-content", "privacy", "payment-issues", etc. The empirical study revealed that value [course-content ("course-content", "value-addition") and facilitator-issues ("quality-of-facilitator", "handling-of-queries")], tradition [trust ("privacy concerns", "authenticity", "reliability")] and risk [payment issues ("payment-failures", "refund issues")] barriers have a notable negative impact on usage-intention. The originality of this works lies in the fact that it explores payment-failure, facilitator-quality, and course-value affecting the acceptance of e-Learning services from the innovation-resistance-theory stance utilising data from various sources (qualitative data from interviews and online reviews and quantitative survey-based data). This work has also discussed different limitations in this study and scope for future research.
\end{abstract}

Keywords: Barriers; Course value; e-Learning; Multi-method approach; Trust; Payment risks; 


\section{Introduction:}

The transition from traditional-based services to online ones has seen a rise of various eServices in almost every sector. Online learning or better known as e-Learning is the use of digital channels like mobile, web, etc. for facilitating education (Garner, 2018). E-Learning services help knowledge seekers to avail the services from anyplace, anytime and thus provide the flexibility of learning. The increasing demand for distance learning courses in the late 2000 s led to the emergence of massive online open courses (MOOCs), and e-learning platforms became a popular medium since 2012 (Pappano, 2012; Tamar, 2013). The expected e-Learning market globally in 2025 is $\$ 325$ billion (McCue, 2018). The popular online learning providers include Coursera, edX, Udacity, Lynda, etc. (Rajpurohit, 2018). In India alone, the number of learners accessing online courses is expected to reach 9.6 million by 2021 (EconomicTimes, 2019). The expected growth of the global e-Learning market is 7.5\% CAGR (compound annual growth rate) and the main reasons behind such growth is the low cost, easy accessibility, flexibility, penetration of internet, and the increasing number of smartphones (Rajput, 2018). However, certain providers face limited adoption due to their limited focus on what learners want (Ennew and Fernandez-Young, 2006; James, 2019; ION, 2019).

In line with what researchers (Ray and Bala, 2019; Ray et al., 2019b) have stated, the eLearning services also face issues from different stakeholders, namely, the providers and the learners. The service-providers face issues like, technological issues, research issues, developing new and recent content (Rana et al., 2014) and bringing more content providers (Tyagarajan, 2016). The users of e-Learning services face issues like, time management, motivation to study, transition from traditional classroom courses to online ones, computer literacy (Kumar, 2015), and technological barriers (Aggarwal, 2017). Additionally, choosing a good course from a mediocre 
one is a confusing task due to the large number of online courses present in e-Learning platforms (Ray et al., 2020a). Although earlier researchers in the e-Learning domain has attempted at exploring the barriers that affect adoption of e-Learning services qualitatively (Oomen-Early and Murphy, 2009; Bai, He, and Kohlbacher, 2018) as well as quantitatively (Al Gamdi and Samarji, 2016; Ali et al., 2018), researchers have noted that qualitative and quantitative techniques suffer from limitations related to sample size and the population spread (Boddy, 2016; Simmons, 2018). A simple solution in this situation is to use the vast amount of textual-data available in various social platforms that captures the learner's perspectives. These issues have motivated us to explore customer perspectives and quantitatively examine the relationships between different barriers and intention. Since technological barrier plays an important role, we have adopted an innovationresistance-theory (IRT) stance. There is only one qualitative study (Ma and Lee, 2018) that has utilised IRT to understand the barriers students face while using open courses. However, studies utilising IRT in e-Learning have not been tested using a quantitative-survey based approach. Additionally, there are limited studies to understand the barriers faced by users while they take up courses from online-learning platforms. For capturing the learner perspectives better, we have utilised data from not only qualitative interviews but also online-learner-reviews and later we have empirically tested how different barriers impact learner's usage intention.

The main research question addressed in this work is: What are the barriers that affect learner's decisions behind the use of eLearning platforms? Two research questions help us to arrive at this main research question: (a) According to the learners (who have used e-Learning services), what are the barriers that impact their intention to use e-Learning services?; and, (b) How can we combine insights from different sources (qualitative interviews, user-generated data, and quantitative survey based data) to examine the barriers affecting usage of e-Learning services? The 
research objectives that drive the research methodology are: First, to utilize the qualitative perspectives of learners from various sources (in-depth interviews and online reviews) and quantitative responses for analysing the barriers affecting learner's decisions related to enrolling in courses offered by e-Learning providers through use of a multi-method approach. The other objective is to overcome the limitation of sample size in qualitative studies for generating themes for the quantitative research in mixed-method approaches by using content analysis on online usergenerated content (UGC).

It is vital to recognise the various barriers impacting the acceptance of e-Learning services. A good knowledge of these barriers will help scholars and practitioners to explore more in other e-Service domains. This study has adopted a multi-method based approach consisting of an initial qualitative study utilising data from both qualitative interviews as well as from online reviews, followed by a quantitative-based approach to assess the barriers. The sample size for qualitative interviews, natural-language-processing (NLP)-based analysis and quantitative analysis were 8 participants, 3227 reviews and 463 respondents respectively. The data from semi-structured interviews and surveys are collected mainly from India. The interviews revealed themes like, “complexity”, “quality-of-facilitator", "value-addition”, "trust", "customer-service", "interface issues". The topic-modeling approach extracted themes like, "technique-of-teaching", "languageof-speaker", “communication”, “course-content", “topic-cover", "privacy", "payment-issues", "fake-reviews", "many-notifications", etc. The important themes generated were utilized to link to the different barriers examined in this study. Results of the quantitative study reveal that value [course-content ("course-content", "value-addition") and facilitator-issues ("quality-offacilitator", "handling-of-queries")], tradition [trust ("privacy concerns", "authenticity", 
"reliability")] and risk [payment issues ("payment-failures", "refund issues")] barriers have a notable negative impact on the motive behind the use of e-Learning platforms.

Section 2 discussed the literature background. Section 3 presents the proposed model and the hypotheses. Section 4 discusses the methodology. Section 5 and 6 reveals the findings of this study and discussion on the findings. It also contains the implications, limitations and scope for further research. Section 7 contains the conclusion.

\section{Review of Relevant Literature:}

e-Learning or better known as online-learning is the use of Internet and technological innovations for delivering knowledge (Liaw, Huang, and Chen, 2007). Mobile-learning refers to the learning approaches using mobile-devices (Pappas, Giannakos, and Sampson, 2019; Almaiah, and Alismaiel, 2019). Another type of learning which is quite common is blended learning, which deals with both online and offline modes for learning activities (Wong, 2019). In addition to understanding the factors, like, authenticity and perceived benefits (Ray et al., 2019a), cognitive and affective aspects, like, ease-of-use, usefulness, etc. (Pappas et al., 2019), student emotions (Pappas, Giannakos, and Mikalef, 2017), etc. that affect adoption of e-Learning services, it is also crucial for service-providers to take note of the barriers that can affect adoption decisions of learners.

Barriers refer to the person's evaluation of potential hindrances he/she might face while using a certain service/product and this affects his/her behavioural intention (Brown, 2005). Researchers

have been studying barriers in various contexts like, healthcare (Brown, 2005), adoption of renewable energy innovations (Reddy and Painuly, 2004), etc. For any service provider it is vital to know the barriers that customer's face because the advancement of technological innovations 
has not only changed the lifestyle of people (Ray et al., 2020b) but has also led to increase in competition in almost every sector (Ray et al., 2019a). The easy accessibility of various internetbased services (Ray and Bala, 2020a) has also increased barriers faced by consumers. Researchers have attempted at exploring the barriers affecting intention in different contexts like, online banking (Laukkanen, 2016). With a growing demand of online courses and the influence of various factors affecting customer's usage intention of online courses like, authenticity, perceived benefits (Ray et al., 2019a), satisfaction, societal pressure (Ray et al., 2020c), etc., understanding the barriers learner's face while using or adopting online courses can help to not only look into the service-gaps but also generate a positive influence on the prospective learners. The most widely used framework to understand the technological barriers is the IRT framework proposed by Ram and Sheth (1989). We will look into these aspects in the next sub-sections.

\subsection{Barriers in e-learning services}

The various widely used e-Learning platforms include Coursera, Udacity, etc. Experts feel that flexibility of learning by e-Learning platforms (EconomicTimes, 2019) and the validity of course certificates in career (Ray et al., 2019a) have led to the increasing demand for e-Learning platforms. The resistance towards acceptance of e-Learning services also includes lack of awareness, unavailability of certification courses and computer-literacy (Learnpick, 2015).

Researchers have also found various barriers affecting acceptance of e-Learning services. Schneckenberg (2010) found that motivation and faculty capabilities affect usage of e-Learning platforms. Muilenburg and Berge (2005) found that motivation, time, support, technical, and administrative issues affect students' intention to use online-learning platforms. In Middle-East countries, researchers found barriers like, infrastructure, limited web-content and copyright-issues 
(Abdelraheem, 2006), language obstacles and technology issues (Ali and Magalhaes, 2008), internet penetration and cost of internet (Mirza and Al-Abdulkareem, 2011). Simuth and SarmanySchuller (2010) found that the limited face-to-face communication between students and teacher and text-based study materials act as a barrier in online-learning. In context of video-based learning (VBL), while Liu, Li, and Carlsson (2010) found that performance based aspects, like, near/long term usefulness, personal innovativeness (Liu et al., 2010) affects adoption, Mikalef, Pappas, and Giannakos (2016) found that the cognitive factors like, social-norms, computer self-efficacy and performance expectancy have a notable direct/indirect impact on adoption. In another study on VBL, Pappas, Mikalef, and Giannakos (2016) found that the variance in adoption is also based on gender differences. Ali et al., (2018) identified 68 unique e-learning barriers like, language, setupcosts, absence of real-time feedback, course-content, pedagogy, student-readiness, computerliteracy, technological difficulty, prior knowledge, technical support, etc. Bai et al., (2018) in a qualitative study on Chinese people, found that technological barriers (equipment and adaptability) had a negative influence on adoption of online-courses. Additionally, flexibility and user-interface affected intention-to-use. In a slightly different context, Alqahtani and Issa (2018) analysed the barriers affecting use of social networking sites as means of education in Saudi Arabia. Ma and Lee (2018) based on a focused-group qualitative study on MOOCs found that usage, value and tradition barrier affect students' usage decision. Sabah (2019) found that while students' motivation aid in adoption of blended learning, individualistic differences can affect use intentions. Regmi and Jones (2020) in their analysis of 57 articles on e-Learning in case of healthcare found that the main barriers are lack of motivation and expectation, lack of technological skills and the suitability of the content/discipline. Limited research has been done on exploring barriers related 
to e-Learning services and there are hardly any empirical studies on exploring the barriers affecting technology usage. This study tries to bridge this gap through use of innovation-resistance-theory.

\subsection{Innovation-Resistance-Theory (IRT)}

IRT, initially proposed by Ram (1987) was later enhanced by Ram and Sheth (1989). IRT is useful in explaining the resistive-behaviour of consumers towards certain innovative services. Ram and Sheth (1989) stated that user's resistance plays a crucial role in deciding the success or failure of innovations. The experience a learner gains from the use of the service can develop a resistivebehaviour in them (Ram and Sheth, 1989) which in-turn can affect their intention to adopt/use eLearning services. Over the years, researchers have used IRT for evaluating the barriers related to various e-Services, like, online-banking (Laukkanen, 2016), online-purchase (Lian and Yen, 2013), teleworking (Meroño-Cerdán, 2016), and mobile-commerce (Hew et al., 2017). IRT states that the resistive-oriented behaviour can be either active or passive (Heidenreich and Handrich, 2015). Active resistance deals with the resistance that arises from the features of the innovation and is studied through functional barriers like usage, value, risk and social barriers ( $\mathrm{Yu}$ and Chantatub, 2016). Passive resistance refers to the barriers that cause a difference of opinion with user's existing beliefs and is studied through psychological barriers like traditional and image barriers (Yu and Chantatub, 2016). Usage barrier deals with the usability-related issues. Value barrier describes the barriers related to benefits provided by the eService. Risk barrier deals with various uncertainties associated with the eService. Social barriers deal with the societal pressure or various social-norms. Tradition barrier demonstrates the resistance a user faces when he/she moves away from his/her usual tradition/culture. Image barrier deals with the various barriers related the e-service brand or image. The penetration of internet has increased the popularity of distance-learning and this has led to the growth of a number of e-Learning providers. 
Apprehending the barriers that impact the use of e-Learning services can help providers take preventive measures to stay ahead in the competition. Existing literature on IRT emphasises the importance of understanding an individual's resistance towards adoption of an innovation (Brahim, 2015) and the comprehensiveness of IRT (Ma and Lee, 2018) makes it a preferred choice among research scholars (Kaur, Dhir, Singh, Sahu, and Almotairi, 2020). There is only one qualitative study (Ma and Lee, 2018) which has utilised IRT through a qualitative study. The authors have found that usage, value and tradition barrier affect students' usage decision. However, the study lacks empirical backing and the perspectives of students from a wide-population. This has motivated us to examine the barriers affecting usage of e-Learning services from the IRT stance.

\section{Proposed Model and Hypotheses Formulation}

The present work has utilized nine constructs separated under five barriers from the IRT perspective, namely, usage barrier (interface-issues, connectivity-issues), value barrier (coursecontent, facilitator-issues), risk barrier (payment-issues), traditional barrier (trust-issues), image barrier (brand-issues, customer service), and usage intention. The themes generated from the qualitative interviews and the UGC (discussed in details in Section 5 and Section 6), namely, "rigid-course-structure”, “course-complexity", “quality-of-facilitator”, "handling-of-queries", “value-addition", “course-content”, "payment-issues", "fake-reviews", "many-notifications", etc. were mapped onto the different barriers stated in the IRT, namely, usage [interface ("complexity", "platform-hangs", “confusing-content") and connectivity issues ("pages take time-to-load", "issues when internet-speed is slow")], value [course-content ("course-content", "career related courses", “course-complexity", "value-added courses") and facilitator-issues ("quality-offacilitator", "handling-of-queries", “technique-of-teaching”, “communication”)], risk [payment 
issues ("payment-failures", "refund issues", "excessive charges", "different price for different users")], tradition [trust ("privacy concerns", "authenticity", "reliability")], and image [customerservice ("handling issues", "executive behaviour", "co-operation of service executives") and brand-issues ("fake information", "many notifications", "irritating advertisements")] barriers to prepare the conceptual model for empirical analysis. The conceptual model is portrayed in Figure 1. The objective is to analyse the impact of the barriers (usage, value, risk, traditional, image) on usage intention.

\section{[INSERT Figure 1 here]}

\subsection{Usage Barrier}

Usage barrier refers to barriers related to usability (Reinherdt et al., 2017). Usage barrier also deals with the service's ease-of-use. The difficulty a user faces while using a service (Rogers, 1983) and adapting to the change brought by the innovation (Laukkanen et al., 2008) also acts as usage barrier. Scholars have noted a negative relation between usage barrier and user's motives in different situations like, adoption of mobile commerce (Moorthy et al., 2017). We have examined interface issues and connectivity issues as part of usage barrier. If the learner faces issues due to reasons like, poor user interface, problem in finding courses, interface hangs, etc. the learner will not adopt the service. Vasuki (2019) found negative impact of interface issues on overall customer experience. Hence, this study proposes:

H1: Interface issues negatively influence usage intention of eLearning services.

Users may also face resistance due to trialability barriers (Moore and Benbasat, 1991), like, connectivity issues. Connectivity issues due to internet connection or issues due to the platform needing more data to load can make the platform slow and result in a dis-satisfied user. Researchers 
have seen that connectivity issues are a major barrier in context of e-services like mobile money service (Tangirala and Nlondiwa, 2019). We feel that connectivity issues will hamper learner's intention to use e-Learning service.

H2: Connectivity issues negatively influence usage intention of eLearning services.

\subsection{Value Barrier}

Value barrier depicts perceived value derived from the service with respect to the cost incurred (Reinherdt et al., 2017). Laukkanen (2016) stated that an innovation offering relative advantage (Rogers, 1983) and superior performance (Ferreira et al., 2014) as compared to other alternatives will be preferred by the customers. Scholars have noted a negative impact of value barriers on intention in contexts like, mobile commerce (Moorthy et al., 2017), online shopping (Lian and Yen, 2014). Based on the themes generated through the qualitative studies, we study two contexts under value barriers, namely, the value-derived-from-course and the facilitator quality.

Value barriers mainly deal with the consumer's perception of the innovation's performance and monetary value with respect to the available alternatives (Ram and Sheth, 1989). While using e-Learning services, users compare prices of courses, and the course content offered by the various e-Learning platforms. If the learners feel that they are not getting the value for money, they will be reluctant to use the service. Researchers (Henderikx et al., 2018; Dai et al., 2020) have found that bad course content is a crucial barrier in context of e-Learning continuance intention. Thus this study proposes:

H3: "Not-so-good" course content negatively influences usage intention of eLearning services. 
The qualitative-based interviews have revealed that facilitator teaching and communication skills affect a person's motives to pursue a particular course. Researchers (Ray et al., 2020b) noted a positive influence on facilitator quality on intention to take up online courses. Researchers have also noted that teaching quality affects not only students' learning (Sandnes and Jian, 2001) but also their satisfaction (Jian and Sandnes, 2009). If the facilitator is not able to teach a particular course properly, learners' will refrain from taking the course. Additionally, if the learners feel that a particular e-Learning platform has more courses where facilitators lack good communication/teaching skills, they will refrain from using that service. Hence, we propose that:

H4: "Not-so-good" facilitators negatively influence usage intention of eLearning services.

\subsection{Risk Barrier}

Risk barriers refer to uncertainties or danger an innovation brings. It is a type of functional risk which refers to cases where the innovation does not work as expected (Reinherdt et al., 2017). Researchers have stated negative influence of risk barriers on user's motives in various contexts like, online purchase (Bianchi and Andrews, 2012), usage of mobile payment (Wong and Mo, 2019), etc. In case of eLearning services, the risk involved is mainly due to payment failure. Researchers have found that online-payment issues affect users' intention to use services like, online-ticket-booking (Sun et al., 2019). Although Teoh et al., (2013) found an insignificant influence of trust and security on usage intention of e-Payment mode, the authors stated that the main challenge lies in continuously meeting consumer expectations. In context of e-Learning services, a learner will refrain from using a service which has a high probability of payment failure while booking a course. Thus this study proposes:

H5: Payment issues negatively influence usage intention of eLearning services. 


\subsection{Traditional Barrier}

Tradition barrier deals with the barriers an innovation creates when it clashes with the individual's tradition or societal norms (Reinherdt et al., 2017). Tradition barrier mainly deals with the trust an individual has on the innovative service since an individual will abstain himself from using a service which he/she cannot trust (Lian and Yen, 2013). Researchers have noted a positive influence of trust on intention in context of mobile payment services (Wong and Mo, 2019) and use of WeChat services (Lien and Chao, 2014). Gupta and Arora (2017) found that traditional barrier negatively affects intention to adopt mobile-shopping. Thus, a customer will be reluctant to use an eService unless he/she develops trust towards that eService (Claudy et al., 2015). Hence, authenticity and validity affects usage of online-learning services (Ray et al., 2019a). Additionally, if the e-Learning service hinders learner's prior beliefs, the user will be reluctant to use the service. Hence, this study supposes:

H6: Trust issues negatively influence usage intention of eLearning services.

\subsection{Image Barrier}

Image barrier deals with the image projected in the minds of the consumers by attributes of the innovation like the origin or identity or brand (Laukkanen, 2016). For example, if users of an e-Learning service consider the service to be unworthy and feel that taking up the service will affect their identity, it will have a negative impact on their intention. The image barriers in context of online-learning services are studied in the form of problematic customer service and brand image of the provider.

Excellent customer service satisfies consumers, resulting in positive purchase intentions (Kuo et al., 2009). Customer service deals with the different measures a service-provider takes to 
handle various issues that customers face. Andreassen and Olsen (2008) found that consumers who have a bad customer-service experience will examine all aspects carefully while using the service again. Grégoire et al. (2015) found that consumers retaliated from the service having bad customer service. In the current study, the following types of customer services result in image barriers: (a) service provider refuses to accept the responsibility for a bad course; (b) customer services do not understand learner's problems, and do not act on learner's feedback or fail to resolve the learner complaints. Thus we propose:

H7: Issues in customer service negatively influences usage intention of eLearning services.

Kleijnen et al. (2009) stated that it's the image of the innovation that affects the decision-making process of consumers. Ram and Sheth (1989) found that if a customer feels that associating with a particular brand will tarnish his/her image in the society, they will refrain from adopting the service. Earlier scholars have noted that image barriers have a negative association with intention in different contexts like, acceptance of mobile commerce (Moorthy et al., 2017). Even for onlinelearning services learners will tend to register and take courses from the provider that have good brand reputation. Thus, this study supposes:

H8: Issues related to e-Service brand image negatively influences usage intention of eLearning services.

\section{Methodology:}

The purpose of this study is to empirically examine the barriers affecting adoption of eLearning services from an IRT stance. In this study, a multi-method approach was undertaken to explore the factors affecting the usage of online courses. The steps followed are summarized in Figure 2. Qualitative studies helps to justify the phenomenon under consideration by extracting 
perspectives of participants (Creswell \& Plano, 2007). However, often in qualitative research it becomes difficult to capture the perspectives of a wider population (Boddy, 2016; Simmons, 2018). This limitation can be overcome by considering the UGC available in different online platforms. An NLP-based approach is used to analyse UGC. This process helps to capture perspectives from a wide population in a short span-of-time. These topics or themes are then utilised to develop measurement items for the quantitative-based analysis.

\section{[INSERT Figure 2 HERE]}

\subsection{Sampling method and sample statistics}

For a good qualitative research, it is necessary to capture the perspectives of "informationrich" participants (Creswell and Plano, 2007). Qualitative data was collected by using a convenient and purposeful sampling approach (Lincoln and Guba, 1985). Purposive sampling helps to gather data from participants by making sure that there is a good representation of the population under study, like, participants from different genders (male, female), participants from different educational backgrounds (high-school, graduate, post graduate/pursuing Ph.D., and working professionals). The participants are mainly Indian students and working professionals.

For the quantitative study, the online questionnaire was floated in mainly three institutes and in different Facebook and WhatsApp groups. 463 responses were received from Indian respondents between April-July 2019. The sample statistics are shown in Table 1.72.79\% of the participants were male, and the participants were mainly in the age-group 21-25 (76.24\%).

[INSERT Table 1 here]

\subsection{Data collection}


Earlier researchers have stated that the choice of data-collection approach is dependent on the information-depth needed for fulfilling the research objectives (Uwizeyimana and Mathevula, 2018). The qualitative data was collected through a semi-structured interview schedule. 8 participants (50\% female) were interviewed. In-depth telephonic interviews were conducted for developing a dialogic partnership between the researcher and the participant (Stokes and Bergin, 2006). The participants were working professionals, post-graduate students and doctoral students who have previously used e-Learning services. The participants were mainly asked about their educational backgrounds, their profession, what issues they faced while using e-Learning platform and what changes according to them can improve e-Learning services.

For getting data from user-generated reviews, the reviews from Coursera 100k dataset (ref: Coursera) were considered. Among the data only those reviews having over hundred words were used. This helped to get a dataset of 3227 reviews.

For the quantitative based analysis, an online questionnaire was distributed among students from mainly three educational institutes and in Facebook groups and WhatsApp. The participants had an idea of e-Learning platforms. A total of 463 responses were received.

\subsection{Data analysis}

For the qualitative analysis, after all the interviews were completed, the qualitative data was analysed using thematic-based analysis. The thematic-based analysis helps to produce a more realistic background by capturing patterns from the qualitative dataset (Braun et al., 2019). Priority was given to themes with higher frequencies during axial coding (Creswell, 2009). Since the dataset is small, thematic-based analysis is done manually by following the steps mentioned by Ravi (2013). The steps are as follows: 
- For each sentence considered, a label/ code was determined for conveying the appropriate meaning related to the study objective.

- Discussion among two scholars helped to determine the common and unique codes.

- Constant comparison of these unique codes helped to chalk-out the most important codes (focused coding).

- The focused codes were arranged based on descending order of priority (axial coding).

- The codes are again checked to ensure that they have captured all the data related to the study objective.

Along with the qualitative data, text analytics was performed on the reviews given by users. Topic-modeling was performed to extract the topics/themes from the user reviews. The topics generated were discussed with another academic expert to generate themes from the UGC. Extracting important themes through qualitative content analysis using text-mining techniques (Serna and Gasparovic, 2018), helps to generate an item pool for the structural model. The steps followed for extracting themes from UGC are as follows:

- Each user review is managed as a separate document in this case.

- Initially pre-processing is performed where reviews in languages other than English are removed. Stop-words, punctuations, and "not so useful words" are also removed.

- Stemming is performed on the cleansed data.

- Latent Dirichlet Allocation (LDA)-tuning is performed to find out the optimal number of topics relevant to each dataset.

- Topic-modeling (using LDA) is performed on the cleansed dataset to generate the topic-terms matrix and the probabilities matrix.

- Discussion among two researchers helps in extracting the useful themes from the topic-terms matrix.

In both the cases for theme generation, the scholars calculated the percentage agreement on the presence of the theme using Boyatzis's (1998) formula: 


$$
\frac{[2 *(\text { no. of times both coders } A \text { and } B \text { saw it present })]}{[(\text { no. of times coder } A \text { saw it present })+(\text { no.of times coderB saw it present })]}
$$

In this study, the minimum threshold decided was 40 percent for considering a code as a theme.

The themes generated in the qualitative analysis were linked to the constructs. Care was taken to generate the themes separately and not have the different barriers in mind while selecting the themes. As mentioned by earlier researchers (Saunders et al., 2009), the item pool was pilot tested on 10 students from an institute in India. The final dataset for SEM based analysis contained 463 respondents.

We have used R 3.6.3 for performing the topic-modeling and SMART PLS v.3.2.8 for performing the structural model analysis.

\section{Results}

The qualitative interviews revealed themes "rigid-course-structure", "complexity", "quality-offacilitator", "handling-of-queries", "value-addition”, “authenticity", "trust", "customer-service", and "interface issues". The topic-modeling approach extracted themes like, "technique-ofteaching", "language-of-speaker", "able-to-answer-queries", "communication", "focus-in-thecontent", “course-needs-improvement", "pages take time-to-load", “course-content”, "platformhangs", “interest-in-course”, “topic-cover", "privacy", "payment-issues", "fake-reviews", "courseduration", "many-notifications", and "difficult-to-understand." These themes were used to frame the conceptual model from the IRT stance.

Results of the quantitative study are summarized in Table 2 and Table 3. The structural equation modeling results showed a good standardized root mean square residual score $(0.078)$ and normed-fit index score (0.701). Also the model factors demonstrated good loadings and 
variation inflation factor scores (see Table 2). The model also showed good average variance extracted, composite reliability and cronbach's alpha scores (all values $>0.5$ ) (See Table 4). The discriminant validity scores show good validity (see Table 3) (Hair et al., 2010, 2013).

[INSERT Table 2]

[INSERT Table 3]

Figure 3 presents the path-coefficients of the various paths. Results reveal a negative relationship between the paths: traditional barriers $\rightarrow$ intention, and value barriers $\rightarrow$ intention, risk barriers $\rightarrow$ intention. All the other paths from usage and image barriers to usage intention respectively revealed a positive association. The hypotheses results showed significant negative influence of value barrier [value-derived-from-course $(\beta=-0.082, p<0.1)$ and facilitator-issues $(\beta=-$ $0.127, p<0.001)$ ], risk barrier [payment issues $(\beta=-0.062, p<0.1)$ ], and tradition barrier [trust $(\beta=-$ $0.075, p<0.01)]$ on intention-to-use e-Learning services. The findings are summarised in Table 4.

\section{[INSERT Figure 3]}

[INSERT Table 4]

\section{Discussion}

This study examined the barriers affecting usage of online-learning services through a multi-method approach. We have extracted themes from the qualitative interviews and the UGC and used them to connect with the different constructs of the conceptual model.

Based on the qualitative-interviews we have generated the themes "rigid-course-structure", “complexity", “quality-of-facilitator", "handling-of-queries", "value-addition”, "authenticity", "trust", "customer-service", and "interface-issues". 
Related to the course, we found three important themes, namely, "rigid-course-structure", "complexity", and "value-addition". "Rigid-course-structure" means that the course-structure designed is not flexible and the service-providers keep using the same content for a long periodof-time. This prevents them from aligning the courses with recent topics and can affect the intention of students. A participant (Male, 23 years old) stated:

"The courses need to be flexible. There are many courses that have the same topics which was present around a year back. I think service-providers need to pay more attention. They should not only update the courses regularly but also keep the topics flexible so that the students can choose the topics they want to learn and pay accordingly."

Participants have also voiced their concern about the "complexity" and "value-addition". While "complexity" of the course refers to difficulty in understanding the course, "value-addition" deals with how the course helps in improving the knowledge of the student, how the course will be helpful in future career, etc. Participants felt that a course which is difficult to understand and which does not add value will not be taken up by prospective learners.

"I have often taken up courses based on the course content but later found out the course content so difficult that I had to take up other courses to understand that. While certain platforms clearly mention the prerequisites to a course, some platforms do not." (Female, 26 years)

“...if a platform doesn't provide more courses which adds value to our knowledge or can help in career course, user will be reluctant to use the platform..." (Male, 30 years)

Regarding the facilitator, based on the comments from two participants, we have selected two themes "quality-of-facilitator" and "handling-of-queries". These themes reveal that it is equally important for the providers to take note of the facilitator quality which includes not only how he 
communicate, how he teaches, how he pronounce and connect with the students, but also how he handles the questions raised by the students. The exemplars from two participants are given below:

"I had faced issues with the facilitator of a course. Although I had paid around 2000 INR for the course, the facilitator quality was so bad that I couldn't understand the topics properly. Based on the preview video you won't get a glimpse of how the facilitator quality is." (Male, 23 years old)

"The providers need to check into whether the faculty taking the course responds to the queries. I had posted a query and have not got any reply yet. I wish I had taken the same course from a different platform." (Female, 28 years)

Participants have also raised concerns regarding "authenticity" and "trust". While authenticity referred to the validity of the course completion certificates in job-market, "I choose a platform based on feedback from others whether the certificate that I will get upon completion of the course will be considered by the companies who will offer me job or not" (Male, 29 years), the "trust" issues refer to different issues like privacy concerns, payment issues, etc. "I have read that providers sell the customer data in return of money. This sometimes worries me because I have given my credit card details while registering for a course." (Female, 29 years).

Participants have also raised concerns related to "customer-service" and "interface-issues". Participants feel that if the customer-service behaviour is not good and they fail to handle customer queries better, users will switch to a different provider. Additionally, participants also feel that if there are "interface-issues" like 'difficulty in searching relevant courses' (Female, 30 years), 'slowness of the platform' (Male, 23 years), 'compatibility of the platform' (Male, 30 years), etc. users will be reluctant to use the services of that particular provider. 
The topic-modeling approach extracted themes like, "technique-of-teaching", "language-ofspeaker", “able-to-answer-queries”, “communication”, “focus-in-the-content", "course-needsimprovement", "pages take time-to-load", "course-content", "platform-hangs", "interest-incourse", “topic-cover", "privacy", "payment-issues", "fake-reviews", "course-duration", "customer-service", "many-notifications", and "difficult-to-understand." Some of the themes generated are in line with what the interview participants have also stated. For example, related to facilitator quality ("technique-of-teaching", "language-of-speaker", “able-to-answer-queries", “communication"), related to course-content ("focus-in-content", "course-needs-improvement", “course-content", "topic-cover", “course-duration", “difficult-to-understand”), related to trust and risk ("privacy”, "payment-issues”), and interface-issues ("platform-hangs", "pages take time-toload"). We also note that users have noted issues related to customer service "getting no support from staff on technical matters or feedback on why a true or false questions is always wrong." One new theme that emerged is "many-notifications" which refers to lots of notifications sent by the providers. This can be really irritating as evident from the review "BUT it is so rude to send emails/notifications/greetings/reminders to me in a very early/late time (e.g., 7AM, 10PM). During that moment, I was waked up frequently by your emails which do NOT include a big deal." Another important theme that emerged from the UGC is "fake reviews", which can often misguide learners to take a particular course, "This course may be misleading aspiring data analysts and scientists: it may give the false impression that, with the tools learned here, you will be able to analyze your data by yourself."

The themes generated from the qualitative studies were linked to different constructs in the conceptual model and a set of eight hypotheses were developed. The hypotheses developed were tested using structural models utilising the data collected through the quantitative-based survey. 
H1 and $\mathbf{H 2}$ investigate the negative relationship between usage barriers, namely interface issues and connectivity issues with motives behind use of e-Learning services respectively. Results show a positive association between the usage barriers and e-Learning services. Thus the hypotheses are not supported by the data. This is unlike what researchers Moorthy et al. (2017), Vasuki (2019) and Tangirala and Nlondiwa (2019) have found. The possible reasons for this result can be that e-Learning users may not face any possible usage barriers. With the advancement of technological innovations and the availability of $4 \mathrm{G}$ services in almost every location, consumers usually do not face issues related to connectivity or interface-loading. Additionally, various eServices have made several technological changes to make the experience better. Hence even when there is some amount of usage barrier but the content is good, learners will continue using the eLearning service.

$\mathbf{H 3}$ and $\mathbf{H 4}$ explore the negative association between value barriers, namely, value-derivedfrom-a-course and facilitator-issues with motives behind use of online-learning services. Findings show a significant negative relationship between the value barriers and usage intention. The findings are in line with what earlier scholars have noted (Lian and Yen, 2014; Morthy et al., 2017). The possible reasons behind a negative influence between a 'not-so-valuable' coursecontent and usage intention are as follows: (a) the negative relation shows that learners seek value from the e-Learning platforms. If the courses present in the e-Learning platform are not good, learners may stop using that particular e-Learning service; (b) learners' now-a-days look for more novel content from different courses in e-Learning platforms which can be helpful for their career growth. E-Learning platforms that are unable to provide novel content will not be preferred by learners. Possible reasons behind the negative association between facilitator-issues and usage intention are as follows: (a) a facilitator teaching a course is equally important. If a facilitator is 
unable to explain the topics properly, learner's will not be able to learn the course properly leading to a dis-satisfied user; (b) the way a facilitator handles learner's queries is another aspect. Platforms where learners' queries are not answered properly will not be preferred by users. Due to the above mentioned reasons, learners' may feel that the value of an e-Learning platform creates a barrier. Additionally, the availability of so many e-Learning providers makes the learner easy to switch to a different provider if they feel that one particular e-Learning service has failed to meet their expectations.

H5 examines the negative relation between risk barriers (payment issues) and usage intention. Findings show a significant negative influence. Earlier scholars have also noted a negative association in contexts like, adoption of m-commerce (Rahman, 2013), e-commerce (Moorthy et al., 2017), etc. The possible reasons can as follows: First, with the advancement of technology users' expect the services to be better. If a transaction gets cancelled due to an issue at the provider's end, it is likely to affect user's usage intention (For e.g., in context of online ticket booking (Sun et al., 2019). Second, payment-issues can lead to uncertainty of the time-period as to when the amount will be reverted back to the learner's account. This creates panic and might result in dis-satisfaction. Third, learners may fear privacy concerns if the e-Learning platform is not preferred by others in his friend's circle. So the learner will refrain from using the service if he/she feels that the transactions might not be secure and might result in loss of his/her privacy.

H6 explores the negative association between tradition barrier (trust issues) and intention to use e-Learning services. Results reveal a significant negative association between tradition barrier and usage intention. This is similar to what earlier scholars (Ma and Lee, 2017; Moorthy et $a l ., 2017$ ) have found. This can be due to the several reasons: (a) learners' feel insecure while using a particular e-Learning service as to how authentic the course will be for them, will the certificate 
provided by the e-Learning service be useful when they apply for job interviews, etc.; (b) learners' also fear paying for a course based on content and then finding out that the e-Learning provider fails to live up to the promise and does not cover the topics in-depth.

H7 and $\mathbf{H 8}$ examined the negative relationship between image barriers (customer service and brand issues) with intention to use online-learning services. Findings show a positive significant impact of image barriers on usage intention. This is however contradictory to what researchers (Laukkanen, 2016; Kleijnen et al., 2009; Ram and Sheth, 1989) have stated in their studies. The possible reasons can be: First, the negligible switching barrier helps users to choose a different e-Learning service if they feel that a particular provider is not performing as expected. Second, in this highly competitive market scenario almost all providers have a good customer service team which solves different issues faced by learners and hence even when a service has certain amount of customer service issues, but the courses offered are highly valuable, learners prefer to choose the particular online learning platform. Third, even when a learner feels that the brand image of a particular e-Learning provider is not good, but the courses offered are valuable, learners will still use the service.

\subsection{Practical Implications}

We now discuss the different practical implications. First, this work has used a multimethod approach. Utilising the multi-method approach will help in reducing the qualitativeapproach limitations of sample-size and population spread. Utilising this method can help marketers and managers to explore various factors related to various topics of interest quite easily and quickly. However, using NLP-based content-analysis to generate themes has been used by various researchers in recent years and can help to get an overview of the themes that reflect user's 
perspectives in a short time-period. This will help organizations to gain a quick overall understanding of the user perspectives related to their service.

Second, this work will help e-Learning providers to understand the barriers to e-Learning platforms and strategize properly for attracting new prospects and retain existing customers. This study sheds light on the association between the various barriers and usage intentions in case of eLearning services. Managers of other e-service providers can utilise the findings to understand factors of importance pertaining to that topic of interest.

Third, results of this work show a negative relation between value, risk and traditional barrier with usage intention. This suggests that managers of e-Learning companies need to establish ways such that users do not feel insecure. Proper timely feedbacks can help understand the customer feelings about the services and help serve the customers better. Understanding the barriers can help organizations manage the service issues that exist and serve the customers better. In this highly competitive market scenario and the negligible switching barrier in context of certain e-services like, e-Learning services, providing quality services (Binsardi and Ekwulugo, 2003) and keeping the learner satisfied is very important for providers. Hence understanding the barriers affecting a service will help providers focus on those aspects which can have a more significant impact on customer's decisions.

\subsection{Theoretical Implications}

This present work has four theoretical implications. First, the present study paves the path for future academicians to explore the multi-method approach in various aspects. This current work has used a multi-method approach by combining the traditional approach (mixed-method approach) with NLP-based content-analysis which will improve the limitation of qualitative 
research related to sample size and population-spread (Boddy, 2016; Simmons, 2018). However, it must be noted that although an NLP-based content-analysis will help to overcome the abovementioned limitations by generating a plethora of themes, it is not suitable to gain an in-depth understanding of the customer's perspectives. Hence, we leave it with the researchers to decide between NLP-based analysis or in-depth interviews or a combination of both.

Second, this work adds value to the existing online learning literature by examining different barriers affecting motives behind the use of the online-learning services. In this competitive market scenario, it is essential to understand both the factors and the barriers that influence usage intention of various e-services. Ray et al., (2019a) have voiced concern regarding the limited studies on understanding students' perspectives behind the choice of online courses from e-Learning platforms. This study will help scholars to explore more on the important barriers found in this study like value, tradition and risk barriers as to how it affects learner's perception of the e-Learning service and how long they will continue using the service when they face such barriers.

Third, this study has utilised the theoretical framework of IRT in context of online-learning services. Ma and Lee (2018) using qualitative interviews from an IRT stance have noted that usage, value and tradition barrier affect students' usage decision. In this study, based on the multi-method approach we note that value, tradition, and risk barriers affect intention to take up online courses. Limited studies have focused on course-content and facilitator-quality. Similar to what researchers have stated, this study also notes that course-content (Henderikx et al., 2018; Dai et al., 2020) and facilitator-quality (Sandnes and Jian, 2001) are important barriers to usage intention. We also note that payment issues and trust factors (authenticity and reliability) affect intention. Future scholars can utilise these factors to analyse students' perspectives. 
Fourth, from the UGC we extract certain themes like "technique-of-teaching", "languageof-speaker", “able-to-answer-queries", “topic-cover", "fake-reviews", "course-duration", "manynotifications", etc. which has not been utilised earlier. Although Schneckenberg (2010) found that motivation and faculty capabilities affect usage of e-Learning platforms, a deeper understanding of topics like "technique-of-teaching", "language-of-speaker", "able-to-answer-queries" would help the researchers extend their work. Other researchers like, Muilenburg and Berge (2005) and Ali and Magalhaes (2008) can benefit from this work by not only looking into technological factors like "many-notifications", but also facilitator skills ("able-to-answer-queries") and course design ("topic-cover"). This study will provide scholars an avenue to generate a vast pool of items for better analysis.

\subsection{Limitations and future directions}

Some limitations of this research are: First, the quantitative data of this work may be subject to common-method bias and response bias due to the same respondent answering to both the dependent and independent variables. In future, researchers can look at other avenues to get rid of the methodological biases, like, longitudinal surveys, experiments, etc. Second, for the NLP-based approach, the themes were generated from the reviews using latent-dirichlet-allocation technique. Researchers in future can use other techniques for better results like latent-semantic-analysis (LSA), hierarchical LSA, etc. In future, researchers can use similar methodology (multi-method approach) in various other studies or market research studies. This methodology can help get views of a wider population easily. In future, researchers can also explore the resistances to other online based services. Third, the mixed-method study was conducted mainly on Indian users. This study can be generalised in future by focusing on other countries which are developed. Fourth, it will be interesting to examine if different types barriers are necessary or sufficient conditions for an 
outcome to occur, and how they relate to intention. To achieve this purpose, future scholars can utilise the fuzzy-set qualitative comparative analysis (fsQCA) (Pappas, Giannakos, Jaccheri, and Sampson, 2017; Papamitsiou, Economides, Pappas, and Giannakos, 2018).

\section{Conclusion}

Research on exploring methodology for utilising the user reviews and comments for exploring various factors of importance, related to various topics, is still new. This article contributes to the existing literature on online learning services by examining the different barriers that impact the intention-to-use e-Learning services. This work has utilised a multi-method approach comprising of qualitative interviews of 8 participants, exploring themes through topicmodeling from 3227 reviews, and responses from 463 e-Learning users. Themes generated from the qualitative study are "rigid-course-structure", "doubt clearing", "complexity level", "pronunciation-of-facilitator", "value-addition", "authenticity", and "interface issues", “technique-of-teaching", "language-of-speaker", “focus-on-the-content”, “course-content", "topic-cover", and "difficult-to-understand". Findings of the quantitative study show that value (course content and facilitator issues), tradition (trust issues) and risk (payment issues) barriers have a notable negative relation with intention to use e-Learning services. This study also discusses various managerial implications like understanding barriers in e-Learning services will help managers focus more on values provided, the risks involved and the trust between the customer and the provider. The study also discusses few limitations and scope for future research.

\section{References:}

Abdelraheem, A.Y. (2006). The implementation of e-learning in the Arab Universities: Challenges and opportunities. In DLI 2006, Tokyo, Japan, pp. 145-154. 
Aggarwal, B. (2017), “4 Challenges For eLearning Developers. eLearning Industry”, eLearning Industry, available at: https://elearningindustry.com/4-challenges-elearning-developers (accessed 30 July 2019)

Al Gamdi, M.A. and Samarji, A. (2016), "Perceived Barriers towards e-Learning by Faculty Members at a Recently Established University in Saudi Arabia," International Journal of Information and Education Technology, Vol. 6 No. 1, pp.23-28.

Ali, G.E. and Magalhaes, R. (2008), "Barriers to implementing e-learning: a Kuwaiti case study", International Journal of Training and Development, Vol. 12 No. 1, pp.36-54.

Ali, S., Uppal, M.A. and Gulliver, S.R. (2018), “A conceptual framework highlighting e-learning implementation barriers," Information Technology \& People, Vol. 31 No. 1, pp.156-180.

Almaiah, M.A., and Alismaiel, O.A. (2019), "Examination of factors influencing the use of mobile learning system: An empirical study," Education and Information Technologies, Vol. 24, pp.885-909.

Alqahtani, S., and Issa, T. (2018), "Barriers to the adoption of social networking sites in Saudi Arabia's higher education," Behaviour \& Information Technology, Vol. 37 No. 10-11, pp.111.

Andreassen, T.W. and Olsen, L.L. (2008), “The impact of customers' perception of varying degrees of customer service on commitment and perceived relative attractiveness," Managing Service Quality: An International Journal, Vol. 18 No. 4, pp.309-328.

Bai, X., He, Y. and Kohlbacher, F. (2018), "Older people's adoption of e-learning services: a qualitative study of facilitators and barriers," Gerontology \& Geriatrics Education, pp.1-17. 
Bianchi, C. and Andrews, L. (2012), "Risk, trust, and consumer online purchasing behaviour: a Chilean perspective," International Marketing Review, Vol. 29 No. 3, pp.253-275.

Binsardi, A. and Ekwulugo, F. (2003), "International marketing of British education: research on the students' perception and the UK market penetration", Marketing Intelligence \& Planning, Vol. 21 No. 5, pp.318-327.

Boddy, C.R. (2016), "Sample size for qualitative research," Qualitative Market Research: An International Journal, Vol. 19 No. 4, pp.426-432.

Boyatzis, R.E. (1998), Transforming Qualitative Information: Thematic Analysis and Code Development, Sage, New York, NY.

Brahim, S.B. (2015), "Typology of resistance to e banking adoption by Tunisian," Journal of Electronic Banking Systems, pp.1-8.

Braun, V., Clarke, V., Hayfield, N. \& Terry, G. (2019), “Thematic analysis”, In Liamputtong, P. (Ed.): Handbook of Research Methods in Health Social Sciences, Springer, Singapore.

Brown, S.A. (2005), "Measuring Perceived Benefits and Perceived Barriers for Physical Activity," American Journal of Health Behavior, Vol. 29 No. 2, pp.107-116.

Claudy, M.C., Garcia, R. and O’Driscoll, A. (2015), “Consumer resistance to innovation-a behavioral reasoning perspective," Journal of the Academy of Marketing Science, Vol. 43 No. 4, pp.528-544.

Coursera (2019), “Coursera 100k Dataset”, available at: https://www.kaggle.com/septa97/100k-courserascourse-reviews-dataset (accessed 15 December 2019) 
Creswell, J.W. \& Plano, C.V.L. (2007), Designing and Conducting Mixed Methods Research, Sage Publications, USA.

Creswell, J.W. (2009), Research Design: Qualitative, Quantitative, and Mixed Methods Approaches, 3rd ed., Sage, Thousand Oaks, CA.

Dai, H.M., Teo, T., Rappa, N.A., and Huang, F. (2020), “Explaining Chinese university students' continuance learning intention in the MOOC setting: A modified expectation confirmation model perspective," Computers \& Education, Vol. 150, pp.N.A.

EconomicTimes (2019), "E-learning platforms slowly changing Indian education landscape", available at: https://economictimes.indiatimes.com/industry/services/education/e-learningplatforms-slowly-changing-indian-education-landscape/articleshow/68850167.cms (accessed 30 July 2019)

Ennew, C.T. and Fernandez-Young, A. (2006), "Weapons of mass instruction? The rhetoric and reality of online learning", Marketing Intelligence \& Planning, Vol. 24 No. 2, pp.148-157.

Ferreira, J.B., da Rocha, A. and da Silva, J.F. (2014), "Impacts of technology readiness on emotions and cognition in Brazil," Journal of Business Research, Vol. 67 No. 5, pp.865-873.

Garner T.A. (2018), “Applications of Virtual Reality”, In: Echoes of Other Worlds: Sound in Virtual Reality. Palgrave Studies in Sound. Palgrave Macmillan, Cham.

Grégoire, Y., Salle, A., and Tripp, T.M. (2015), "Managing social media crises with your customers: The good, the bad, and the ugly," Business Horizons, Vol. 58 No. 2, pp.173-182. 
Gupta, A. and Arora, N. (2017), "Understanding determinants and barriers of mobile shopping adoption using behavioral reasoning theory," Journal of Retailing and Consumer Services, Vol. 36, pp.1-7.

Hair, J., Black, W., Babin, B., and Anderson, R. (2010), Multivariate data analysis (7th ed.). Upper Saddle River: Pearson Prentice Hall.

Hair, J.F., Ringle, C.M. and Sarstedt, M. (2013), "Partial least squares structural equation modeling: rigorous applications, better results and higher acceptance," Long Range Planning. Vol. 46, pp.1-12.

Heidenreich, S., and Handrich, M. (2015). "What about passive innovation resistance? Investigating adoption-related behavior from a resistance perspective," Journal of Product Innovation Management, Vol. 32 No. 6, pp.878-903.

Henderikx, M., Kreijns K., and Kalz M. (2018), “A Classification of Barriers that Influence Intention Achievement in MOOCs," In: Pammer-Schindler V., Pérez-Sanagustín M., Drachsler H., Elferink R., Scheffel M. (eds) Lifelong Technology-Enhanced Learning. vol 11082. Springer, Cham.

Hew, J-T., Tan, G.W-H., Lin, B. and Ooi, K-B. (2017), “Generating travel-related contents through mobile social tourism: Does privacy paradox persist?" Telematics and Informatics. Vol. 34 No. 7, pp.914-935.

ION (2019). "Strengths and Weaknesses of Online Learning," Available at: https://www.uis.edu/ion/resources/tutorials/online-education-overview/strengths-andweaknesses/ (accessed 5 July 2020) 
James, A. (2019). "Daily Challenges Faced By E-Learning Professionals," Available at: https://www.appsandreports.com/blog/challenges-faced-by-elearning-professionals/ (accessed 5 July 2020)

Jian, H.L. and Sandnes, F.E. (2009), Taiwanese and Norwegian Engineering students' self-image of academic abilities, grades and course satisfaction. 2009 IEEE International Conference on Industrial Engineering and Engineering Management.

Kaur, P., Dhir, A., Singh, N., Sahu, G., and Almotairi, M. (2020), "An innovation resistance theory perspective on mobile payment solutions," Journal of Retailing and Consumer Services, Vol. 55, pp. 102059 .

Kleijnen, M., Lee, N. and Wetzels, M. (2009), "An exploration of consumer resistance to innovation and its antecedents," Journal of Economic Psychology, Vol. 30, pp.344-357.

Kleijnen, M., Lee, N. and Wetzels, M. (2009), "An exploration of consumer resistance to innovation and its antecedents," Journal of Economic Psychology, Vol. 30, pp.344-357.

Kumar, S. (2015). “5 Common Problems Faced By Students In eLearning And How To Overcome Them," available at: https://elearningindustry.com/5-common-problems-faced-by-students-inelearning-overcome (Accessed 30 July 2019)

Kuo, Y-F., Wu, C-M., and Deng, W-J. (2009), "The relationships among service quality, perceived value, customer satisfaction, and post-purchase intention in mobile value-added services," Computers in Human Behavior, Vol. 25 No. 4, pp.887-896. 
Laukkanen, P., Sinkkonen, S. and Laukkanen, T. (2008), "Consumer resistance to internet banking: Postponers, opponents and rejecters," The International Journal of Bank Marketing, Vol. 26 No. 6, pp.440-455.

Laukkanen, T. (2016), “Consumer adoption versus rejection decisions in seemingly similar service innovations: The case of the Internet and mobile banking," Journal of Business Research, Vol. 69 No. 7, pp.2432-2439.

LearnPick (2015), "E-learning in India: Benefits, Prospects and Challenges," available at: https://www.learnpick.in/blog/e-learning-in-india (accessed 30 July 2019)

Lian, J.-W. and Yen, D.C. (2013), "To buy or not to buy experience goods online: Perspective of innovation adoption barriers," Computers in Human Behavior, Vol. 29 No. 3, pp.665-672.

Lian, J.-W. and Yen, D.C. (2014), “Online shopping drivers and barriers for older adults: Age and gender differences," Computers in Human Behavior, Vol. 37, pp.33-143.

Liaw, S.-S., Huang, H.-M., and Chen, G.-D. (2007), "An activity-theoretical approach to investigate learners' factors toward e-learning systems," Computers in Human Behaviour, Vol. 23, pp.1906-1920.

Lien, C.H. and Cao, Y. (2014), “Examining WeChat users' motivations, trust, attitudes, and positive word-of-mouth: Evidence from China," Computers in Human Behavior, Vol. 41, pp.104-111.

Lincoln, Y.S. and Guba, E.G. (1985), Naturalistic Inquiry, Sage, Beverly Hills, CA.

Liu, Y., Li, H., \& Carlsson, C. (2010). "Factors driving the adoption of m-learning: An empirical study," Computers \& Education, Vol. 55 No. 3, pp.1211-1219. 
Ma, L. and Lee, C.S. (2018), "Understanding the Barriers to the Use of MOOCs in a Developing Country: An Innovation Resistance Perspective," Journal of Educational Computing Research, Vol. 57 No. 3, pp.1-20.

McCue, T.J. (2018), “E Learning Climbing To \$325 Billion By 2025 UF Canvas Absorb Schoology Moodle," available at: https:/www.forbes.com/sites/tjmccue/2018/07/31/elearning-climbing-to-325-billion-by-2025-uf-canvas-absorb-schoologymoodle/\#5604274a3b39 (accessed 30 July 2019)

Meroño-Cerdán, A.L. (2016), "Perceived benefits of and barriers to the adoption of teleworking: peculiarities of Spanish family firms," Behaviour \& Information Technology, Vol. 36 No. 1, pp.1-12.

Mikalef, P., Pappas, I.O., \& Giannakos, M. (2016). “An integrative adoption model of video-based learning." The International Journal of Information and Learning Technology, Vol. 33 No. 4, pp.219-235.

Mirza, A. and Al-Abdulkareem, M. (2011), "Models of e-learning adopted in the Middle East", Applied Computing and Informatics, Vol. 9 No. 2, pp.83-93.

Moorthy, K., Suet Ling, C., Weng Fatt, Y., Mun Yee, C., Ket Yin, E. C., Sin Yee, K. and Kok Wei, L. (2017), "Barriers of Mobile Commerce Adoption Intention: Perceptions of Generation X in Malaysia," Journal of Theoretical and Applied Electronic Commerce Research, Vol. 12 No. 2, pp.37-53. 
Moore, G.C. and Benbasat, I. (1991), "Development of an Instrument to Measure the Perceptions of Adopting an Information Technology Innovation,” Information Systems Research, Vol. 2 No. 3, pp.192-222.

Muilenburg, L.Y. and Berge, Z.L. (2005), "Student barriers to online learning: A factor analytic study," Distance Education, Vol. 26 No. 1, pp.29-48.

Oomen-Early, J. and Murphy, L. (2009), "Self-Actualization and E-Learning: A Qualitative Investigation of University Faculty's Perceived Barriers to Effective Online Instruction," International Journal on E-Learning, Vol. 8 No. 2, pp.223-240.

Papamitsiou, Z., Economides, A.A., Pappas, I.O., \& Giannakos, M.N. (2018), "Explaining learning performance using response-time, self-regulation and satisfaction from content: an fsQCA approach, "In Proceedings of the 8th international conference on learning analytics and knowledge (pp. 181-190).

Pappano, L. (2012). "The Year of the MOOC," The New York Times, available at: https://www.nytimes.com/2012/11/04/education/edlife/massive-open-online-courses-aremultiplying-at-a-rapid-pace.html?pagewanted=all\&_r=0 (accessed 30 July 2019)

Pappas, I.O., Mikalef, P., \& Giannakos, M.N. (2016). “Video-Based Learning Adoption: A Typology of Learners.”In SE@ VBL@LAK (pp. 34-41).

Pappas, I.O., Giannakos, M.N., and Sampson, D.G. (2019), "Fuzzy set analysis as a means to understand users of 21st-century learning systems: The case of mobile learning and reflections on learning analytics research," Computers in Human Behavior, Vol. 92, pp.646-659. 
Pappas, I.O., Giannakos, M.N., and Mikalef, P. (2017), "Investigating students' use and adoption of with-video assignments: lessons learnt for video-based open educational resources," Journal of Computing in Higher Education, Vol. 29 No. 1, pp.160-177.

Pappas, I.O., Giannakos, M.N., Jaccheri, L., and Sampson, D.G. (2017), "Assessing student behavior in computer science education with an fsQCA approach: The role of gains and barriers," ACM Transactions on Computing Education (TOCE), Vol. 17 No. 2, pp.1-23.

Rahman, M.M. (2013), "Barriers to m-commerce adoption in developing countries- a qualitative study among the stakeholders of Bangladesh," The International Technology Management Review, Vol. 3 No. 2, pp.80-91.

Rajpurohit, O. (2018), "List of Best Online Course Providers Worldwide in 2019", available at: https://unboxcareer.com/list-of-best-online-course-providers-2019/ (accessed 30 July 2019)

Rajput, M. (2018), “How Big Is The eLearning Market And The Role Of Mobile Apps?” available at: https://elearningindustry.com/big-elearning-market-role-mobile-apps (accessed 30 July 2019)

Ram, S. (1987), “A Model of Innovation Resistance”, In NA - Advances in Consumer Research Volume 14, eds. Melanie Wallendorf and Paul Anderson, Provo, UT : Association for Consumer Research, pp.208-212.

Ram, S. and Sheth, J.N. (1989), "Consumer Resistance to Innovations: The Marketing Problem and its solutions," Journal of Consumer Marketing, Vol. 6 No. 2, pp.5-14.

Rana, H., Rajiv and Lal, M. (2014), "E-learning: Issues and Challenges," International Journal of Computer Applications, Vol. 97 No. 5, pp.20-24. 
Ravi, P.K. (2013), The Encyclopedia of Cross-Cultural Psychology, 1st ed., John Wiley \& Sons, Inc., US.

Ray, A., and Bala, P.K. (2019), "Use of NLP and SEM in Determining Factors for E-Service Adoption," In Y. Akgül (Ed.), Structural Equation Modeling Approaches to E-Service Adoption (pp. 38-47). Hershey, PA: IGI Global. doi:10.4018/978-1-5225-8015-7.ch003

Ray, A., Bala, P.K. and Dasgupta, S.A. (2019a), "Role of authenticity and perceived benefits of online courses on technology based career choice in India: A modified technology adoption model based on career theory," International Journal of Information Management, Vol. 47, pp.140-151.

Ray, A., Bala, P.K., Dasgupta, S.A. and Sivasankaran, N. (2019b), "Factors influencing adoption of e-services in rural India - perspectives of consumers and service providers," Journal of Indian Business Research, Vol. 12 No. 2, pp.215-230.

Ray A., Bala P.K., and Dasgupta S.A. (2020a), "Psychological Analytics Based Technology Adoption Model for Effective Educational Marketing”, In: Rana N. et al. (eds) Digital and Social Media Marketing. Advances in Theory and Practice of Emerging Markets. Springer, Cham.

Ray, A., Bala, P.K., and Dwivedi, Y.K. (2020b), "Exploring values affecting e-Learning adoption from the user-generated-content: A consumption-value-theory perspective," Journal of Strategic Marketing, pp.1-23. 
Ray, A., Bala, P.K., Dasgupta, S.A., and Srivastava, A. (2020c), "Understanding the factors influencing career choices in India: from the students' perspectives," International Journal of Indian Culture and Business Management, Vol. 20 No. 2, pp.175-193.

Ray, A., and Bala, P.K. (2020a), "Social media for improved process management in organizations during disasters," Knowledge and Process Management, Vol. 27 No. 1, pp.63-74.

Reddy, S., and Painuly, J. (2004), "Diffusion of renewable energy technologies—barriers and stakeholders' perspectives," Renewable Energy, Vol. 29 No. 9, pp.1431-1447.

Regmi, K., \& Jones, L. (2020). "A systematic review of the factors - enablers and barriers affecting e-learning in health sciences education.” BMC Medical Education, Vol. 20 No. 1, pp.1-18.

Rogers, E.M. (1983), Diffusion of innovations (3rd ed.). New York: Free Press.

Sabah, N.M. (2019), "Motivation factors and barriers to the continuous use of blended learning approach using Moodle: students' perceptions and individual differences," Behaviour \& Information Technology, Vol. Ahead of print. 1-24.

Sandnes, F.E., and Jian, F.H-L. (2001), "Quantitative web-based teaching tools for progress management and evaluation," International Conference on Engineering Education August 610, 2001 Oslo, Norway. pp.1-6.

Saunders, M.N., Lewis, P. and Thornhill, A. (2009), Research Methods for Business Students, 5th ed. Pearson Education India. 
Schneckenberg, D. (2010), "Overcoming barriers for eLearning in universities-portfolio models for eCompetence development of faculty," British Journal of Educational Technology, Vol. 41 No. 6, pp.979-991.

Serna, A., and Gasparovic, S. (2018), "Transport analysis approach based on big data and text mining analysis from social media," Transportation Research Procedia, Vol. 33, pp.291-298.

Simmons, A.E. (2018), "The Disadvantages of a Small Sample Size", available at: https://sciencing.com/disadvantages-small-sample-size-8448532.html (accessed on 5 April 2020)

Simuth, J. and Sarmany-Schuller, I. (2010), “Online Learning Barriers,” In: Iskander M., Kapila V., Karim M. (eds) Technological Developments in Education and Automation. Springer, Dordrecht.

Stokes, D. and Bergin, R. (2006), "Methodology or 'methodolatry'? An evaluation of focus groups and depth interviews," Qualitative Market Research: An International Journal, Vol. 9 No. 1, pp.26-37.

Sun, S., Law, R. and Zhong, L. (2019), "Mobile Payment Failure during Travel," Journal of China Tourism Research, pp.1-17.

Tamar, L. (2013), "Universities Abroad Join Partnerships on the Web," New York Times, available at: https://www.nytimes.com/2013/02/21/education/universities-abroad-join-mooccourse-projects.html\# (accessed 30 July 2019) 
Tangirala, S., and Nlondiwa, S. (2019). The Utilization of Mobile Money Services in Small Scale Enterprises:A Case Study. European Journal of Business and Management Research, 4(6). https://doi.org/10.24018/ejbmr.2019.4.6.145

Teoh, M-Y.W., Chong, S.C., Lin, B., and Chua, W.J. (2013), "Factors affecting consumers' perception of electronic payment: an empirical analysis," Internet Research, Vol. 23 No. 4, pp.465-485.

Tyagarajan, S. (2016), “eLearning Market in India - Challenges \& Opportunities," iamwire. available at: http://www.iamwire.com/2016/10/elearning-market-in-india-challengesopportunities/120567 (accessed 30 July 2019)

Uwizeyimana, D.E. and Mathevula, N.S. (2018), "Factors contributing to female educators' underrepresentation in school management positions in Lulekani Circuit, Limpopo Province, South Africa”, International Journal of Indian Culture and Business Management, Vol. 16 No. 1, pp.71-97.

Vasuki, B. (2010). A Case study on the effect of information technology related interface issues on overall guest experience in Hyatt Place hotels in the U.S. UNLV Theses, Dissertations, Professional Papers, and Capstones. P.429. Available at: https://digitalscholarship.unlv.edu/thesesdissertations/429

Wong, W.H. and Mo, W.Y. (2019), “A Study of Consumer Intention of Mobile Payment in Hong Kong, Based on Perceived Risk, Perceived Trust, Perceived Security and Technological Acceptance Model," Journal of Advanced Management Science, Vol. 7 No. 2, pp.33-38. 
Wong, R. (2019), "Basis psychological needs of students in blended learning," Interactive Learning Environments, Vol. Ahead of Print. pp.1-15.

Yu, C.S. and Chantatub, W. (2016), “Consumers's resistance to using mobile banking: evidence from Thailand and Taiwan," International Journal of Electronic Commerce Studies, Vol. 7 No. 1, pp.21-38. 
Table 1. Sample statistics of quantitative data

\begin{tabular}{|c|c|c|c|}
\hline \multicolumn{2}{|l|}{ Criteria } & \multirow{2}{*}{$\begin{array}{l}\text { Frequency } \\
337\end{array}$} & \multirow{2}{*}{$\begin{array}{l}\text { Percentage } \\
72.79 \%\end{array}$} \\
\hline Gender: & Male & & \\
\hline & Female & 126 & $27.21 \%$ \\
\hline \multirow[t]{3}{*}{ Age (in years): } & $<20$ & 63 & $13.61 \%$ \\
\hline & $21-25$ & 353 & $76.24 \%$ \\
\hline & $>25$ & 47 & $12.95 \%$ \\
\hline \multirow{4}{*}{$\begin{array}{l}\text { Educational } \\
\text { Background: }\end{array}$} & Pursuing/completed higher secondary level & 18 & $3.89 \%$ \\
\hline & Pursuing/completed graduate level & 418 & $90.28 \%$ \\
\hline & Pursuing/completed masters level & 8 & $1.73 \%$ \\
\hline & $\begin{array}{ll}\text { Pursuing/completed } & \text { doctorate } \\
\text { (PhD/equivalent) } & \end{array}$ & 19 & $4.10 \%$ \\
\hline \multirow{4}{*}{$\begin{array}{l}\text { Economic } \\
\text { Background: }\end{array}$} & Poor & 9 & $1.94 \%$ \\
\hline & Middle Class & 392 & $84.67 \%$ \\
\hline & Rich & 8 & $1.73 \%$ \\
\hline & Prefer not to say & 54 & $11.66 \%$ \\
\hline \multirow{4}{*}{$\begin{array}{l}\text { Usage } \\
\text { Frequency: }\end{array}$} & Very rarely & 54 & $11.66 \%$ \\
\hline & Once-or-twice a month & 55 & $11.88 \%$ \\
\hline & Once-a-week & 130 & $28.08 \%$ \\
\hline & Almost everyday & 224 & $48.38 \%$ \\
\hline \multirow{4}{*}{$\begin{array}{l}\text { Usage } \\
\text { Duration: }\end{array}$} & Less-than-a-month & 143 & $30.89 \%$ \\
\hline & Less-than-six-months & 168 & $36.28 \%$ \\
\hline & Less-than-a-year & 37 & $7.99 \%$ \\
\hline & More-than-a-year & 115 & $24.84 \%$ \\
\hline
\end{tabular}


Table 2. Measurement items, factor loadings, Variation Inflation Factor (VIF).

\begin{tabular}{|c|c|c|c|}
\hline $\begin{array}{l}\text { Study } \\
\text { Measures }\end{array}$ & Measurement Items (for e-Learning services) & Loadings & VIF \\
\hline \multirow{2}{*}{$\begin{array}{l}\text { Interface } \\
\text { Issues }\end{array}$} & Are complicated to use. & 0.959 & 3.479 \\
\hline & The platforms often hang. & 0.962 & 3.479 \\
\hline \multirow{2}{*}{$\begin{array}{l}\text { Connectivity } \\
\text { Issues }\end{array}$} & Take a long time to load items. & 0.947 & 2.278 \\
\hline & Do not work properly when internet speed is slow. & 0.922 & 2.278 \\
\hline \multirow{2}{*}{$\begin{array}{l}\text { Course } \\
\text { Content }\end{array}$} & The course content of the course is not adequate. & 0.922 & 1.971 \\
\hline & Platforms often lack good valuable courses. & 0.923 & 1.971 \\
\hline \multirow[t]{2}{*}{$\begin{array}{l}\text { Facilitator } \\
\text { Issues }\end{array}$} & $\begin{array}{l}\text { If I need special attention in a course, providers fail to do } \\
\text { that. }\end{array}$ & 0.948 & 1.591 \\
\hline & $\begin{array}{l}\text { The facilitator way of teaching and communication skills } \\
\text { affects my interest in the course. }\end{array}$ & 0.830 & 1.591 \\
\hline \multirow{2}{*}{$\begin{array}{l}\text { Payment } \\
\text { Issues }\end{array}$} & The order often gets cancelled after payment is confirmed. & 0.666 & 1.135 \\
\hline & It is a common to experience payment failures. & 0.930 & 1.135 \\
\hline \multirow[t]{2}{*}{ Trust Issues } & I do not trust e-Learning services. & 0.951 & 2.111 \\
\hline & The information provided in the platform is not reliable. & 0.903 & 2.111 \\
\hline \multirow[t]{2}{*}{ Brand Issues } & $\begin{array}{l}\text { Fake reviews and ratings have influenced me choose the } \\
\text { wrong course. }\end{array}$ & 0.832 & 1.495 \\
\hline & $\begin{array}{l}\text { I receive too many notifications and messages from } \\
\text { eLearning services. }\end{array}$ & 0.933 & 1.495 \\
\hline \multirow{2}{*}{$\begin{array}{l}\text { Customer } \\
\text { Service }\end{array}$} & Customer service executives have little cooperative attitude. & 0.920 & 1.749 \\
\hline & $\begin{array}{l}\text { Customer service often refuses to take responsibility for } \\
\text { wrong course contents taught. }\end{array}$ & 0.898 & 1.749 \\
\hline \multirow[t]{2}{*}{ Intention } & I may use eLearning service more frequently in future. & 0.950 & 2.634 \\
\hline & eLearning services are useful to me. & 0.941 & 2.634 \\
\hline
\end{tabular}


Table 3. AVE, CR, CA, and discriminant validity of the various constructs

\begin{tabular}{|c|c|c|c|c|c|c|c|c|c|c|c|c|}
\hline & AVE & CR & $\mathrm{CA}$ & $\mathrm{BI}(\mathrm{IB})$ & CI(UB) & CS(IB) & $\mathrm{FI}(\mathrm{VB})$ & $\mathrm{II}(\mathrm{UB})$ & $\mathrm{PI}(\mathrm{RB})$ & Trust(TB) & INT & $\mathrm{CV}(\mathrm{VB})$ \\
\hline $\mathrm{BI}(\mathrm{IB})$ & 0.781 & 0.877 & 0.730 & $0.884^{*}$ & & & & & & & & \\
\hline CI(UB) & 0.874 & 0.933 & 0.857 & 0.769 & $0.935^{*}$ & & & & & & & \\
\hline $\mathrm{CS}(\mathrm{IB})$ & 0.827 & 0.905 & 0.791 & 0.630 & 0.704 & $0.909 *$ & & & & & & \\
\hline FI(VB) & 0.794 & 0.885 & 0.757 & 0.325 & 0.383 & 0.412 & $0.891 *$ & & & & & \\
\hline $\mathrm{II}(\mathrm{UB})$ & 0.922 & 0.959 & 0.916 & 0.728 & 0.758 & 0.689 & 0.425 & $0.960 *$ & & & & \\
\hline $\mathrm{PI}(\mathrm{RB})$ & 0.654 & 0.786 & 0.513 & 0.265 & 0.319 & 0.362 & 0.630 & 0.346 & $0.809^{*}$ & & & \\
\hline Trust(TB) & 0.860 & 0.925 & 0.841 & 0.366 & 0.476 & 0.579 & 0.396 & 0.559 & 0.346 & $0.927 *$ & & \\
\hline INT & 0.894 & 0.944 & 0.881 & 0.771 & 0.822 & 0.612 & 0.177 & 0.707 & 0.140 & 0.318 & $0.945^{*}$ & \\
\hline $\mathrm{CV}(\mathrm{VB})$ & 0.851 & 0.920 & 0.825 & 0.468 & 0.575 & 0.595 & 0.569 & 0.642 & 0.487 & 0.704 & 0.386 & $0.923 *$ \\
\hline
\end{tabular}

Note: $\mathrm{AVE}=A$ verage-variance-extracted; $\mathrm{CR}=$ Composite reliability; $\mathrm{CA}=$ Cronbach's alpha; $\mathrm{IB}=\mathrm{Image}$ barrier; $\mathrm{RB}=\mathrm{R}$ isk barrier; $\mathrm{TB}=$ Tradition barrier; UB=Usage barrier; INT=Intention-to-use; VB=Value barrier; BI=Brand Issues; CI=Connectivity Issues; $\mathrm{CS}=$ Customer Service; FI=Facilitator Issues; II=Interface Issues; PI=Payment Issues; CV=Course-content value.

*Note: The values of the diagonal elements are squared root of the AVE scores for the respective items and it is higher than the other correlations in that row. 
Table 4. Hypotheses result from the quantitative analysis.

\begin{tabular}{|c|c|c|}
\hline Hypotheses: Path & $\beta$ - value, $p$-values & Result \\
\hline H1:Interface Issues $\rightarrow$ Intention & $\beta$-value $(0.210), \mathrm{p}<0.001$ & Refuted \\
\hline $\mathrm{H} 2$ :Connectivity Issues $\rightarrow$ Intention & $\beta$-value $(0.555), \mathrm{p}<0.001$ & Refuted \\
\hline H3:Course-content $\rightarrow$ Intention & $\beta$-value $(-0.082), \mathrm{p}<0.1$ & Accepted \\
\hline H4:Facilitator Issues $\rightarrow$ Intention & $\beta$-value $(-0.127), \mathrm{p}<0.001$ & Accepted \\
\hline H5:Payment Issues $\rightarrow$ Intention & $\beta$-value $(-0.062), \mathrm{p}<0.1$ & Accepted \\
\hline H6:Trust Issues $\rightarrow$ Intention & $\beta$-value $(-0.075), \mathrm{p}<0.01$ & Accepted \\
\hline H7:Customer Service $\rightarrow$ Intention & $\beta$-value $(0.074), \mathrm{p}<0.01$ & Refuted \\
\hline H8:Brand Issues $\rightarrow$ Intention & $\beta$-value $(0.269), \mathrm{p}<0.001$ & Refuted \\
\hline
\end{tabular}


Figure 1. The proposed model (Adapted from Ram and Sheth, 1989)

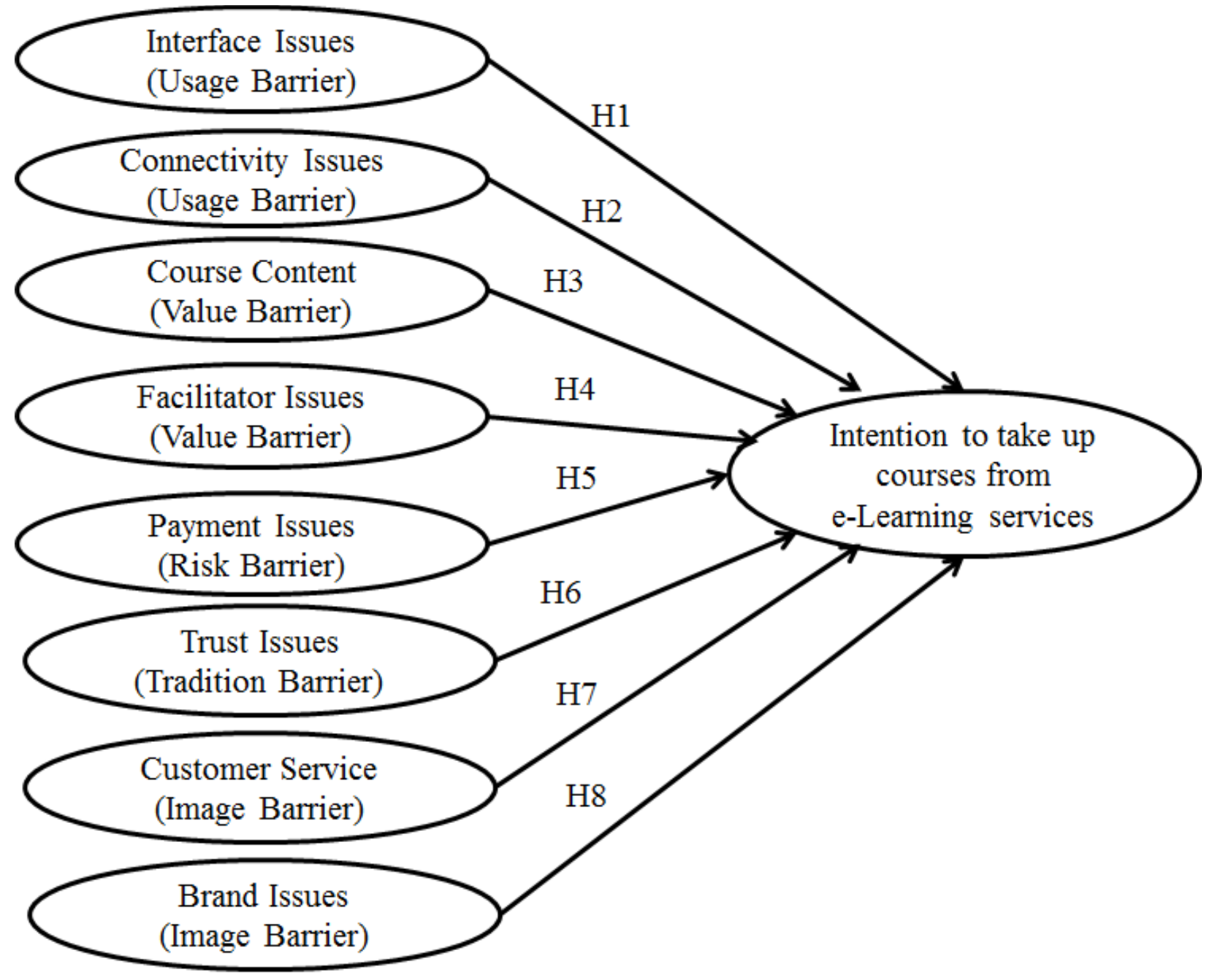


Figure 2. Methodology followed in this study

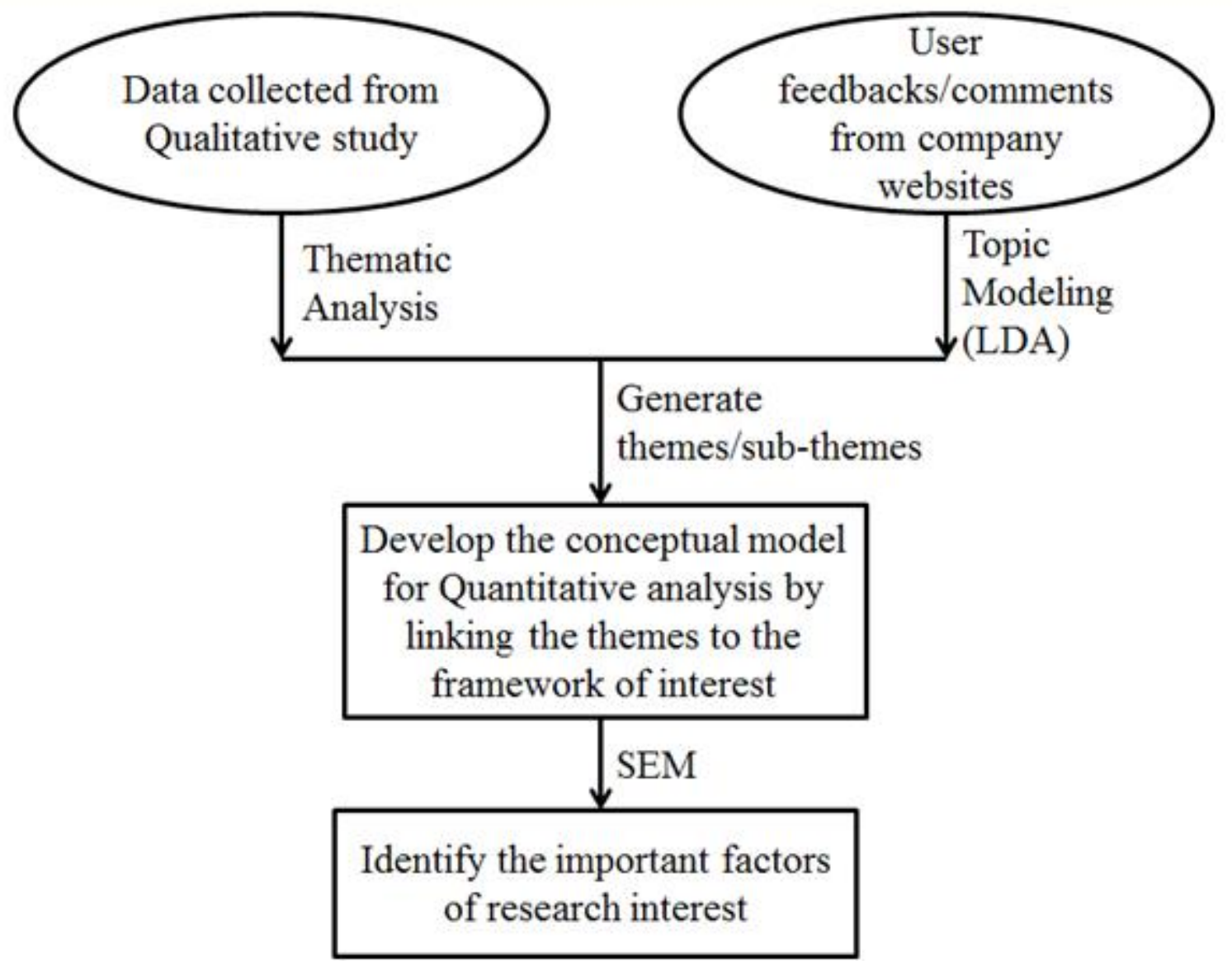

Note: $\mathrm{LDA}=$ Latent Dirichlet Algorithm, $\mathrm{SEM}=$ Structural Equation Modeling 
Figure 3. The path coefficients in the proposed model

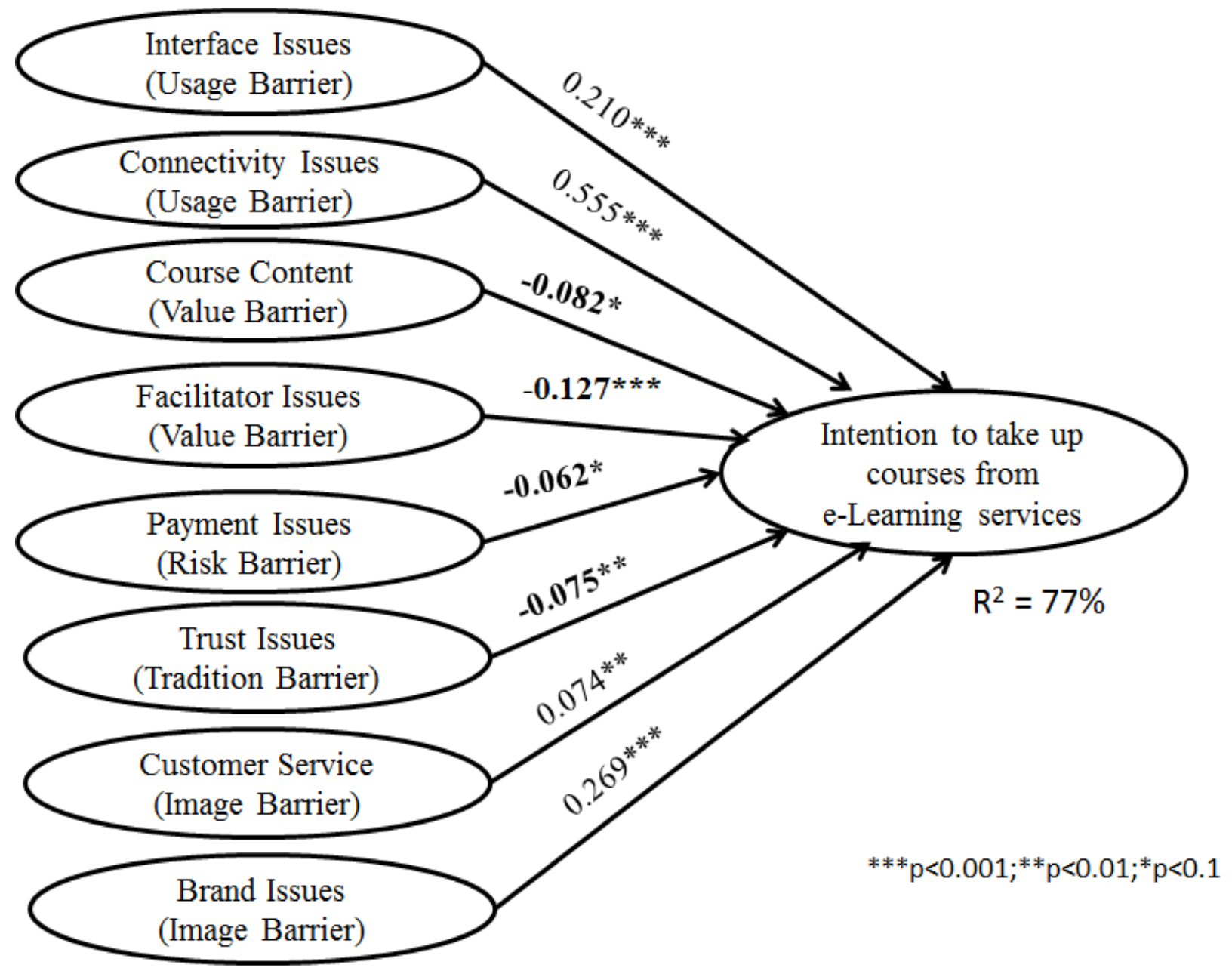




\section{Figure Captions:}

Figure 1. The proposed model (Adapted from Ram and Sheth, 1989)

Figure 2. Methodology followed in this study

Figure 3. The path coefficients in the proposed model 